\title{
Why learn business ethics?- Students' conceptions of the use and exchange value of applied business ethics
}

\author{
Sadanand Varma ${ }^{1}$ (D)
}

Received: 13 October 2016 / Accepted: 29 April 2019 / Published online: 7 May 2019

(C) The Author(s) 2019

\begin{abstract}
Applied Business Ethics is a core module for business undergraduate students in an internationalised university business degree programme from the United Kingdom (UK) taught at a Private Higher Education Institution (PHEI) in Singapore. Students, who are working adults undertaking this part-time degree, are assessed purely on the application of theoretical knowledge through essays that show evidence of their ability to apply theory in workplace ethical dilemmas. This pilot study explores the utility of the module in terms of use and exchange value. It was conducted in two phases as an empirical qualitative research. First, an email survey was sent to students, who had already graduated, to gather impressions of the module using open-ended questions. Based on the responses, semi-structured interviews of a purposive sample of four students were carried out to unearth insights on use and exchange value of the module through their stories. The study suggests that a key determinant of use value is workplace utility of the knowledge that has been gained. Over time, consistent derivation of use value translates to exchange value as long-term behaviour changes in the individual create positive workplace outcomes. The study also recognised the powerful influence of organisational culture in determining whether ethical thinking translates into ethical action, which also has a direct bearing on perceptions of use and exchange value. The findings of this study provide an insight to the understanding of the motivations of working adults attending the Applied Business Ethics module on a part-time basis. Having this understanding, it will be possible to further structure the module, in terms of positioning, delivery and assessment, to enable these students to become better managers when dealing with real-world workplace ethical issues.
\end{abstract}

Keywords Applied business ethics · Use value · Exchange value · Organisational culture

Sadanand Varma

sadanandvarma9@gmail.com

1 Lancaster University, Lancaster, UK 


\section{Introduction}

Applied Business Ethics is a core module for business undergraduate students in an internationalised university business degree programme from the United Kingdom (UK) taught at a Private Higher Education Institution (PHEI) in Singapore. The module, which carries ten module points, is a field of ethical theory that deals with the application of moral principles in real-life workplace situations (Buckley 2013, p. 695). Students are assessed purely on the application of theoretical knowledge through essays that show evidence of their ability to apply theory in workplace ethical dilemmas. Several practitioner tutors (Macfarlane 2011; Whitchurch 2009) teach the module, and while they use the same core text and content slides, they vary their lectures and seminars by sharing their unique experiences. A key challenge of this module is translating "abstract theory into a workable tool for business practitioners" (Hasnas 1998, pp. 19-20), and this sometimes makes rationalising its usefulness in the real world a challenge.

The continued occurrence of corporate ethical misconduct, from the Enron accounting fraud in 2001, the Volkswagen emission scandal in 2015, to the more recent creation of 1.5 million fake accounts by Wells Fargo employees in 2017, was largely because business decisions were carried out without clear ethical considerations (Arce and Gentile 2015, p. 535). These events and occurrences seem to suggest that business ethics should be a key feature in the higher education curricula of potential business leaders (Crane 2004, p. 149; Godsey 2007, p. 55). The real concern is whether ethics education actually makes a difference in the way individuals make ethical decisions in the workplace. Some scholars argue that ethical values (or the lack thereof) have already been shaped prior to entry into higher education (Saat et al. 2010, p. 40). However, evidence from a study of Malaysian accountants, though not definitive, seems to suggest that the completion of an ethics course does make students more ethically sensitive (Saat et al. 2010, p. 53). This notion of a positive correlation between ethics education and ethical sensitivity is also supported by Gautschi III and Jones (1998), as well as Parks (1993), in their empirical assessments of the effectiveness of business ethics education.

Education is supposed to prepare students for life and teach things that are useful in employment (Winch 2002, p. 101). This aim does, in most instances, address the younger generation workers' view of employment as an instrumental outcome (Winch 2002, pp. 103-104). It seems, therefore, that the exchange value, or the future realisable value, of business ethics takes precedence over its use value, or inherent value. This conceptual separation of use value and exchange value arises from the phenomenon of commodification (Skeggs 2004, p. 77), where the notion of finding meaning in education, in this instance business ethics, because it is an "intrinsically valuable activity" (Winch 2002, pp. 102-104), is viewed as a divergent notion from being able to realise the exchange value of that education for future employment (Skeggs 2004, p. 77).

This pilot study builds on previous work done on the impact of business ethics education (Ma 2013; Royaee et al. 2013) and was conducted to seek a better understanding of the perceived utility of the Applied Business Ethics module that is taught to undergraduate students and the factors that determine that utility, using insights from the stories of four part-time undergraduate students who are working adults in 
Singapore. This paper will first discuss literature on business ethics in higher education and then elaborate on the research methodology, after which the stories will be analysed to examine whether the applied business ethics module supports existing literature on the effectiveness of ethics education.

\section{Theoretical framework}

\section{The case for and against business ethics in higher education}

Milton Friedman once argued that the "ethical duty of business people is to maximise profit", and, therefore, having managers study ethics was irrelevant and a waste of time (Buckley 2013, p. 696; Friedman 2002, p. 11; Hooker 2004, p. 75). His position was premised on the logic that managers are trained only to make profit and not social policy; hence, it is their duty to pursue that sole purpose of maximising profit (Friedman 2002, pp. 7-8). He therefore concluded that the focus on profits will remove any motivation for students to study ethics, as the subject seemingly had no relevance to their careers (Hooker 2004, p. 84). He believed that the only motivation managers respond to in the workplace is financial and legal incentives (or disincentives) and not lessons from ethics in the classroom (Hooker 2004, p. 75).

However, his argument ignores the responsibility that managers have in evaluating the ethical impact of their business decisions and acting on those decisions accordingly (Gentile 1993, pp. 81-82; Hooker 2004, pp. 77-78; Mulligan 1986, p. 266). In some sense, Friedman (2002) confuses social ethics with business ethics, or more precisely, the use of the term social responsibility "as a synonym for businesses or a business person's ethical obligations" (Hasnas 1998, p. 20). He also does not take into consideration how attitudes to work and notions of fairness and obedience are shaped by the cultural context and environment (Hooker 2004, pp. 79-81). Friedman's beliefs of business ethics might be attributed to the fact that his ideas were formed in the 1970s where there was less consciousness of such issues in the business world.

To his credit, however, Friedman (2002, p. 11) alludes to the notion of social responsibility when he argues in his concluding comments that a business is expected "to use its resources and engage in activities designed to increase its profits so long as it stays within the rules of the game, which is to say, engages in open and free competition without deception or fraud". This is consistent with contemporary expectations where businesses are expected to adapt to the changing values and needs of their stakeholders to retain legitimacy while still making a profit (Buckley 2013, p. 696; Freeman 2004, p. 231; Hasnas 1998, p. 21; Luthar et al. 1997, p. 205).

This expectation raises the issue of the need for business ethics to be taught in higher education in the first place. Etzioni (2002, p. B4), in his critical review of the effectiveness of ethical education in business schools, posited that there was an overall decline in the moral standards in the business sector. This is especially evident from the increased occurrence of ethical misconducts (Jennings 1999, p. 25) despite higher education business students being schooled in business ethics. Supporting a similar view, Luthar et al. (1997, p. 214), in their empirical study of the ethical attitudes and perceptions of undergraduate business freshman and seniors, noted that the latter were more sceptical of the real-world usefulness of business ethics. This phenomenon was 
attributed to the seniors' exposure to real-world work experience, which heightened their sense of pragmatism; hence, the argument that business ethics has no relevance in one's career (Hooker 2004, p. 84).

Therefore, a key concern for any form of ethical education is whether it can be taught, especially in higher education. One school of thought suggests that because personal values have already been set by the time individuals enter higher education, any ethical education will have little impact on their values or values development (Hooker 2004, p. 82; Luthar et al. 1997, p. 208; Saat et al. 2010, p. 40). Ethical education is deemed as ineffective and therefore unnecessary because moral character is formed and developed by the time an individual reaches adulthood and cannot be changed (Godsey 2007, p. 56; Hooker 2004, p. 84). Business students, in particular, are used to being given the right answer by way of models and frameworks, as would be the case in most business modules, but, in business ethics, they need to contend with the notion of "it depends", which is not something these students are used to (Hooker 2004, pp. 85-86). Furthermore, the manner in which ethics education is positioned in the overall university curriculum in relation to other modules also shapes the relative importance of this subject (Gurvitsh et al. 2017, p. 81; Macfarlane and Ottewill 2004, p. 343; Nastase and Gligor-Cimpoieru 2013, p. 195; Sims and Brinkmann 2003, p. 73). It is important that ethics education is not seen as being divergent to management studies (Gentile 1993, p. 82; Parks 1993, p. 55).

On the other hand, the argument against ethical education does not take into account how cognitive development continues to shape moral development, inducing a change in behaviour that allows students to distinguish between right and wrong at the workplace (Adkins and Radtke 2004, p. 280; Gautschi III and Jones 1998, p. 212; Green and Weber 1997, p. 777; Saat et al. 2010). There is evidence that the teaching of ethical concepts, in particular, the use of real business scenarios, has a positive impact on students' ethical development and their ability to understand and apply ethical concepts at the workplace (Allen et al. 2005, pp. 176-179; Freeman et al. 2009, p. 39; Green and Weber 1997, pp. 777-778; Warnell 2010, p. 78). Specifically, moving away from purely intellectual approaches of teaching ethics to one of practical application on the ground, such as the Giving Voice to Values Approach (Arce and Gentile 2015, p. 473; Gentile 2014, pp. 43-44; Gentile 2017, p. 473), scenario-based case studies and work-based assignments that require application of ethics theory improve their sensitivity to ethical issues (Nastase and Gligor-Cimpoieru 2013, p. 193; Saat et al. 2010, p. 53).

It is acknowledged, however, that the understanding of and the ability to apply ethical reasoning does not necessarily translate into action in a real workplace scenario (Allen et al. 2005, pp. 176-179; Jones 1991, p. 368; Ma 2013; Nastase and GligorCimpoieru 2013, p. 195; Warnell 2010, p. 79). The next segment will explore this further from the lens of use and exchange value and how that perception of value influences orientation to business ethics in the real world.

\section{Perceptions of the use and exchange value of business ethics}

Utility of business ethics An important aspect of accepting the relevance of business ethics in higher education is its utility at the workplace in terms of the impact it has on task performance. Winch (2002, pp. 102-104) suggests that the current generation 
views employment as an instrumental outcome, which is in tension with the notion of education as an "intrinsically valuable activity", where education is viewed as a nonutilitarian pursuit largely for personal satisfaction and growth. Therefore, the knowledge the student receives as part of business ethics education only has value if it is seen to provide an output or has an impact on task performance that is better than if that knowledge was not available. This use value, or value-in-use, is derived from the effect of use or from the benefit of use (De Jong and Ferguson-Hessler 1996, p. 105; Repo 1986a, b, pp. 375-376; Skeggs 2004, p. 89). Although this idea of use value originated from the utility derived from consuming a good, which was inherently tied into its physical properties, the concept can also apply to knowledge gained in the classroom (Skeggs 2004, p. 77). Sometimes, this knowledge has realisable future benefit to the individual, meaning it has exchange value, which may be something enduring like lifelong skills or abilities.

These ideas, however, seem to suggest that use and exchange value are different (Skeggs 2004, p. 77). An alternate view is that use and exchange value are indeed two parts of a whole that are not mutually exclusive (Keen 1993, p. 110). If something has no value in itself, which means it has no use value, then it is unlikely to be exchanged. Also, the effort required to derive benefit through exchange determines the exchange value (Keen 1993, p. 110; Repo 1986a, b, p. 377). Hence, if knowledge derived in the classroom does not appear to have workplace utility, or even some future benefit to the individual, that knowledge will be discarded once the immediate utility of deriving the educational qualification is gained, or until some environmental trigger forces the individual to draw on that knowledge.

In the working world, however, use and exchange value cannot be viewed as clinically as has been discussed. As much as the individual may find value in what has been taught, there are a number of internal, or self-driven, and external, or situational, factors (Rawwas and Isakson 2000, pp. 321-324; Ross Jr and Robertson 2003, pp. 214-217) that shape that leap from understanding the value of knowledge and actually deriving it at the workplace.

Self-perception and ethical orientation A key driver of individuals' perceptions of the importance of business ethics is also partly driven by self-perception of their own ethical status. Those who feel that they are already ethical individuals are likely to treat business ethics education as a waste of time (Adkins and Radtke 2004, p. 282; Rawwas and Isakson 2000, p. 322) and, hence, are likely to make judgements in an ethical dilemma using common sense, which may not always be morally acceptable. They do not see any use value of ethics education since the outcomes of their daily decisionmaking have not changed. The perceived lack of use value will translate to a lack of exchange value (Keen 1993, p. 110).

Having said that, however, these same individuals can be shaped by the organisational environment to emulate "socially desirable responses" (Sinha and Hassan 2015, p. 109) that would result in ethically appropriate behaviours.

Workplace ethics in the real world Sauser Jr (2013) describes four types of organisational cultures, namely the defiant, the negligent, the compliant, and the organisation of character, each of which shapes organisational and individual ethical orientation in a different manner. Organisations that demonstrate a culture of defiance 
are unlikely to believe in the need for ethical behaviour and, to some extent, may discourage or even impede such behaviour amongst their employees (Sauser Jr 2013, p. 15). Such an unsafe environment is unlikely to draw traction for raising ethical issues, even if the individual believes that it is the right thing to do, since job preservation would be higher on the individual's agenda.

There are many organisations that demonstrate overt and formal expression of ethical codes, and even conduct ethics training (Delaney and Sockell 1992, p. 720; Wotruba et al. 2001, p. 59), but do not actively engage in the internalisation of ethical conduct; their ethical codes and programmes are relegated to being "window dressing" (Wotruba et al. 2001, p. 61). These organisations are, at best, compliant, where leaders do not agree with the ethical policies but will demonstrate "a grudging sort of acceptance" to keep within the law (Sauser Jr 2013, p. 15).

Organisations of character, on the other hand, provide an environment for pro-active ethical behaviour, where leaders who are committed to ethical conduct institutionalise the organisation's ethical codes and programmes and shape employees' attitudes, through education, training and role modelling (Delaney and Sockell 1992, pp. 720 723; Sauser Jr 2013, pp. 16-17). These organisations demonstrate both espoused and lived standards of ethical behaviour and engage in "purposive action" by continuously communicating within their organisation and reviewing these standards (Sauser $\mathrm{Jr}$ 2013, pp. 18-20; Wotruba et al. 2001, p. 60).

Defiant organisational culture would inevitably shape attitudes where unethical behaviour is tolerated, or even promoted, in the name of profit (Adkins and Radtke 2004, p. 280; Caza et al. 2004, p. 170), while compliant organisations only provide a façade of ethical compliance. Notions of use and exchange value of ethical education are unlikely to gain traction in these organisations. Organisations of character, however, provide fertile ground for the converted to participate in ethical behaviour and reap the benefits of their ethics education and will force the non-believers to at least comply with organisational ethical norms (Sinha and Hassan 2015, p. 108).

\section{Designing and conducting the research}

The purpose of this research was to understand how part-time undergraduate working adults, in Singapore, perceived the knowledge gained from the Applied Business Ethics module in relation to its use in the workplace, and the reasons for these perceptions. Using this backdrop, the research question was phrased as such:

"What are the factors that influence part-time undergraduate students' perceptions of use and exchange value of the knowledge, from their Applied Business Ethics module, at their workplace?"

This pilot study was positioned as a small-scale qualitative empirical research, using an interpretivist paradigm, with the data being collected in two distinct phases. The first phase involved an email survey requiring short qualitative responses, while the second 
phase involved in-depth face-to-face semi-structured interviews of a purposive sample from the first phase.

In the first phase, using a non-probability sampling approach (Couper 2000, p. 477), email surveys were sent to a list-based sample of fifteen students who had graduated from the degree programme. The sample selected was anecdotally representative of the demographics of a normal cohort (Akerlind 2005, p. 103), in terms of gender, where female students made up approximately $60 \%$ or more of the cohort, as well as distribution of local and international students. The latter were primarily on an employment pass or were permanent residents in Singapore and represented approximately $20 \%$ of the normal demographics. The survey had five open-ended questions, to which the respondents were required to give brief qualitative answers. The questions focused on the following areas:

a. understanding of the module objectives;

b. lessons learned from the module;

c. opportunities for using the theory at the workplace;

d. examples of application of the theory; and

e. usefulness of the theories in the real world.

The purpose of this phase was to identify the diversity of views in the sample rather than the distribution so that the sample could be further shortlisted to do an in-depth qualitative analysis. This method was particularly useful for the "exploration of meanings and experiences" (Jansen 2010). Of the fifteen email requests made, a total of nine replied, of which two were male and the remaining seven were female students.

The initial data that emerged suggested that the lessons from the business ethics module were indeed useful in the workplace, although the respondents also indicated that how ethical decisions actually manifested in the workplace were also influenced by individual and situational factors (Rawwas and Isakson 2000, pp. 321-324; Ross Jr and Robertson 2003, pp. 214-217). What needed to be developed further as data was the qualitative descriptions of these individual and situational factors that would add richness to the data made available through the email surveys.

Therefore, in the second phase of data collection, a series of stories were derived from a purposive sample (Denzin and Lincoln 1994, p. 451; Smith and Eatough 2007, p. 40) of four students from the first phase. The sample comprised two female students, one who was a Singapore citizen and one a foreigner who was a permanent resident, and two male students, one who was on a professional employment permit while the other was of Caucasian origin but has been a Singapore citizen for well over twenty years. Their ages ranged between the late twenties and fifties. The sample also represented an array of industry and work experience, which has a bearing on how ethical issues are dealt with at the workplace. This voluntary sample was kept small to ensure that every voice was heard with "justice" (Creswell 2002, p. 49). These stories were the primary source of data that contributed to the findings in this pilot study.

Stories, in the form of narratives, were used as a method in this research (Gallagher 2011, p. 49) because individuals best make sense of their world through stories (Bailey and Tilley 2002, p. 575). Individuals use stories to organise information, knowledge and experience and use these same stories to communicate their thoughts with others (Bruner 1991, p. 4; Yoder-Wise and Kowalski 2003, p. 37). It was recognised that there 
might be some selective sharing either because of assumed understanding or the author's position as their tutor during the module. Nevertheless, anything that was shared was considered as "revealing truths" that could be interpreted to understand the individuals' orientations and application of what they had learned in the classroom at the workplace (Alvermann 2000, p. 131).

The stories were collected through face-to-face semi-structured interviews that allowed idiographic examination of the individuals' unique lived experiences (Falk 1956, pp. 53-60). These interviews presented a space to narrate their stories, their "ways of knowing and being", without judgement or interpretation by the researcher (Kvale and Brinkmann 2009, pp. 153-155; Lewis 2011, pp. 505-506). To facilitate this space, the students were viewed as "experiential experts" (Kvale and Brinkmann 2009, p. 16; Lester 1999) and "knowledgeable informants" (Sabri 2010, p. 194) who served as a legitimate source to explore the data required without adhering strictly to the interview guide.

The interviews, each with duration of approximately thirty minutes, were digitally taped and transcribed by the author. To mitigate the ethical danger of misrepresenting or distorting the students' perspectives, it was important to represent their voice through quotations (Creswell 2013, pp. 99-101; Kvale and Brinkmann 2009, pp. 272-274). The transcripts were also anonymised, and pseudonyms were used to maintain confidentiality (Kvale and Brinkmann 2009, pp. 186-187).

The analysis was conducted through several readings of the transcribed narratives to gain a holistic perspective of the individuals' lived experiences. This was intended to flesh out the participants' perceptions of the utility, if any, of the knowledge they had gained in the module when dealing with ethical dilemmas at the workplace. The research was also focused on finding out if the knowledge they had gained had a perspective beyond its practical use, namely, as an instrument of personal growth. In order to do that, themes, within each story, and common themes across stories, were identified (Bailey and Tilley 2002, p. 576), and these themes were refined to seek patterns of inter-connectedness. The intention was to unearth underlying meaning from the individuals' experiences that could be aggregated into core themes that could then be informed by the literature that was reviewed.

This study recognised several inherent limitations. Most significant was the author's induced bias as an insider (Smyth and Holian 2008), having taught the module, resulting in certain preconceived notions of the perceived value of the knowledge from the module. Hence, the meaning making of the individuals' lived experiences, both from the survey data as well as the interviews, was inevitably subjective, shaped by the author's own meaning making and expectations (Blythe et al. 2013, pp. 8-9). A mitigating action was to ensure not to lend too much focus on the story in a way that neutralised the actual data within the story (Lee 2015, p. e1). Specific effort was made to distinguish between the actual data and the author's own interpretation as a researcher (Creswell 2013, p. 8; Smith and Eatough 2007, pp. 35-38).

One particular challenge was ensuring that every narrative had a voice in the final research write-up (Creswell 2002, p. 49). To mitigate this, "analytical objectivity" was exercised (Blythe et al. 2013, p. 11) by balancing the voices that could not be represented, with the author's commentaries, based on the whole rather than the parts of the narratives (Alvermann 2000, p. 134; Gallagher 2011, p. 49). This also took into 
consideration the subjectivity of the interview data (Alvermann 2000, p. 131; Blythe et al. 2013, p. 10).

Finally, this study did not also take into consideration pedagogical quality, both in terms of the construct of the curriculum or the teaching methods. The theories underlying the Applied Business Ethics module are not the most intuitive, and the impact of the tutor simplifying the concepts, or using teaching methods that allowed connection to workplace or even life application, was not factored in this study (Allen et al. 2005; Balotsky and Steingard 2006). Nevertheless, the data that was collected provided ample material for more in-depth studies.

\section{Insights from the stories}

This section will first examine how perceptions of the value of business ethics are unfolded through the stories of four individuals, whose names have been replaced with pseudonyms. They had recently graduated with a business degree, where Applied Business Ethics was a core module. The insights derived from these stories will then be informed by the theory that was discussed previously.

\section{The people}

Mary, who is in her late twenties, is a foreign-born national who has been a Singapore Permanent Resident for a number of years. Her early years of education were in hospitality and she recently graduated with a business degree. Her work experience spans primarily the service industries, like the hotel industry and pharmaceutical sales, and she is now working as a sales manager in nutrition and healthcare products.

Vincent heads an aerospace repair centre of a multi-national company set up in Singapore. He is a foreign national who has worked in Singapore for several years as an expatriate. His early working experience was in the medical industry as a software quality engineer, and the remainder of his career was spent in various aerospace companies both overseas and in Singapore. He is in his early fifties.

Harry is in his early fifties and has spent a good part of the last two decades in Singapore, as is a citizen. Although foreign-born, he is married to a Singaporean. He is from a technical and engineering background, having spent almost his entire career in the oil and gas industry, specifically oil drilling. He continues to work in a management position in an oil and gas multi-national company.

Tracy has had various career experiences in the service industry, ranging from information technology programming, car sales and as a stewardess in a renowned airline. Born a Singaporean, she is in late thirties, and is currently working as a manager in medical equipment repair sales.

\section{Perceptions of the value of business ethics}

The stories uncovered five major themes that could explain the perceptions and orientations of these individuals in relation to business ethics. These are framing common sense knowledge, workplace utility, organisational environment, building character and perceived importance of ethics education. 
Framing common sense knowledge A common pattern running through the stories was the notion that these individuals had been making ethical decisions in the past, using what could be inferred as common sense knowledge. The knowledge derived from the Applied Business Ethics module provided a frame to this common sense knowledge.

"Actually, we were doing this all our life or we have done this before ... theories help you to understand the decision that you have taken, whether you have actually taken the right decision or not."

(Mary)

"In the past, before I attended this class, I didn't know there was this thing called ethics of duties. I am supposed to do because I was paid to do so. But after class, then I know there is this thing called ethics of duties."

(Tracy)

The knowledge formed a basis by which this common sense could be better understood. Vincent's revelation of a right decision, from one perspective, possibly being a wrong decision, from another perspective, was instructive.

"But I kind of learned that just because something is right doesn't necessarily mean that it is right. There are alternate views ..."

(Vincent)

Workplace utility A re-emerging theme in the stories was the perceived importance of workplace utility. One perspective from Mary was when the knowledge gained from the ethics education was perceived as actually being applicable at the workplace.

"I did not know that ethics was important but when I started doing one of our modules with ethics then I learned the actual importance of it; how to actually apply it ... I also learned that when you are on a management level and you have to make a certain decision ... means that basically making a decision that doesn't hurt the party you are actually deciding on."

(Mary)

For Harry, the entire experience of looking at things from an ethical perspective was refreshing, and he saw the value of immediate application at the workplace.

"After learning some of the theory, I started using them. I think it should be more than just theory; it should be practised."

(Harry)

In both these instances, knowledge from ethics education was seen as having utility at the workplace, which seemed to reinforce the value of ethics education.

On the other hand, the perceived lack of workplace utility diminishes the value of the knowledge gained in the ethics education. While Tracy shared Harry's perspectives 
on workplace utility, she also felt certain aspects of the theory were too amorphous to have practical application at the workplace.

"... virtue ethics, everybody must do and all but you can't determine one person's character from the whole galaxy. So I think virtue ethics is not so relevant in terms of in society."

(Tracy)

Vincent echoed a similar sentiment, referring to his perceived usefulness of the theory on Kohlberg's levels of moral development.

"The Kohlberg one I felt wasn't that useful because I just didn't find that particular part to be so relevant."

(Vincent)

Hence, the perceived and experienced utility of ethics education at the workplace seems to surface as an important link between use and exchange value.

Organisational environment The organisational environment has a strong influence on the attitudes and responses to ethical issues. At the extreme end of the spectrum is the oil and gas industry, where ethical issues were perceived as not even being part of the agenda. Harry had a clear and curt response when asked how the oil and gas industry deals with ethical issues.

"We ignore them!"

(Harry)

He felt that the oil drilling industry was a rough environment that bred rough attitudes.

"It was a very macho sort of environment, where people were bullied, punched and kicked, and that's normal."

(Harry)

Similarly, when organisations are seen as being contrived in their conduct of ethics education, scepticism about ethics education is reinforced.

“ ... as I say my company does ethics training, but it is not to that level of detail, but pretty superficial."

(Vincent)

Such experiences have the potential of forming negative impressions that may spill over to the classroom and create preconceived notions of ethics education.

The stories also highlighted some genuine attempts by organisations to put in place ethical training and education in order to shape ethical attitudes at the workplace.

“Actually, part of our company's policy is to give ethics training every year."

(Vincent) 
Scenario-based problems were used, but there were standard answers that had to be given, else the employee was asked to re-do the problem until the right answer was achieved. Both Vincent and Harry seem to feel that the effort was more of a façade to stay out of trouble rather than an actual attempt at shaping behaviours.

"They are expecting certain answers, and if you don't get them, you have to re-do it. It's a bit contrived ... we had to do this because we have a lot of Government contracts and the Government expects you to do certain things."

(Vincent)

"I don't recall anybody in my company telling me about the company's ethics policies, and these are the issues, and this is how you deal with it ... I think it's just for show."

(Harry)

Organisations that take such approaches as perceived as focusing on the business or financial goals rather than embed ethical practices.

"To me it is the financial benefit that the company is concerned about ... .You don't want to do it because you don't want to get caught, you don't want to lose the contract."

(Vincent)

Unfortunately, in extreme cases, some of these organisations threaten the safe space required for ethical issues to be raised.

"If you actually understood ethics, and brought it up and said this was a mistake, they would say that it is time for you to leave."

(Harry)

Hence, the stories seem to suggest that organisational culture has a powerful bearing on whether the lessons acquired during ethics education actually bear value at the workplace.

Building character Some of the stories articulated long-term value of ethics education, particularly in the manner in which the knowledge shaped their character. Tracy was one who felt that she made decisions with little consideration for others. She believes that the knowledge from the ethics education has made a positive impact on shaping her behaviour.

"It made be become a much more responsible person." (Tracy)

Harry took on an entirely different orientation towards workplace ethical issues. There was a particular incident where he was asked by his company to gather evidence from a customer to fire an employee, even though the customer did not make a complaint. He stood his ground and fought the issue to keep the employee citing unethical practice. 
"It was unethical but I think people need to see that they have rights, as a company, as a person, in the whole scheme of things. But I didn't understand until this module came along and I thought that was not ethically right." (Harry)

This is in spite of the industry having a track record of letting go of people who stand up to the organisation. Harry is still employed and doing well. He feels that the change in his attitude and behaviour was because he saw the lasting value in the ethics education he had received.

Perceived importance of ethics education The stories seem to suggest that ethics education, whether in the classroom or in the workplace, was an important part of the perceived value of ethical behaviour at the workplace.

“... people will always practise unethical behaviour unless you teach them this is what we are all about as a company."

(Harry)

Vincent reflected on an ethical decision-making model that was taught and how it provided clarity on how ethical dilemmas should be handled.

"So it kind of does focus you on what is important, and then you move on to make a decision because you know that is the way it is supposed to be. Whereas if you haven't done the course you probably may not go to that step."

(Vincent)

Unfortunately, the manner in which the Applied Business Ethics module was positioned, in terms of overall weightage in the undergraduate programme, manifested in some unintended perceptions of its value.

"It is like it is not important, like it is only ten points for this module." (Harry)

"But what disappointed me was that it was only ten per cent of the marks, which kind of shows to me people don't take this as seriously as they should." (Vincent)

This low weightage seemed to suggest that the Applied Business Ethics module was less important than other modules like Marketing or that it was a simple module that students would find easy to receive a pass grade.

Tracy, however, provides a refreshing view where she views every subject as being equally important to her education, regardless of the module's weightage.

"Number one, I will never check the points. To me every subject is important." (Tracy) 
Vincent goes a step further suggesting that more weight be given to ethics education in the contemporary business environment.

"It is such a powerful module when you look at the realism ... Switch it around and make Marketing smaller and give more weightage to the Ethics module." (Vincent)

Nevertheless, education, or the infusion of educated people, presumably also schooled in ethics, seems to have an impact on changing even a difficult organisation like that from the drilling business.

"People's call are changing; to treat people and to treat the system in the countries with some respect. So it is creeping in as people are educated; you got to educate people."

(Harry)

\section{What do the stories tell us?}

There are two major insights that can be derived from the patterns within and across the stories. Patterns from the study seem to suggest that workplace utility is a key determinant in shaping perceptions of use and exchange value of ethics education. This theme surfaces consistently in all the four stories. Secondly, organisational influence seems to play a direct role in shaping perceptions of value, particularly use value, are manifested in the workplace.

\section{Workplace utility determines use value}

A major theme shared across all the stories is the importance of knowledge being useful. The students' ability to apply ethics knowledge from the classroom into the workplace is the primary driver determining its use value, and this is consistent with the literature reviewed (De Jong and Ferguson-Hessler 1996, p. 105; Repo 1986a, b, pp. 375-376; Skeggs 2004, p. 89). However, when they do see a consistent positive impact in their workplace, this use value increases. Over time, exchange value is derived when some of the knowledge they have gained translates into lifelong skills or behavioural changes that have a positive impact on their work and perhaps even personal lives (Skeggs 2004, p. 77). This would then suggest that ethics education could indeed be an "intrinsically valuable activity" (Winch 2002, pp. 102-104).

The reverse is also true, as was described by Tracy and Vincent. Their experience suggests that scepticism in real-world usefulness of business ethics sets in because of challenges applying their ethics knowledge at the workplace, particularly those concepts that are more conceptual in nature (Luthar et al. 1997, p. 214). The perceived inability to connect use value inadvertently translates to exchange value not being realised. This supports the notion that use and exchange value are not mutually exclusive and are two parts of a whole (Keen 1993, p. 110). 
As Mary and Tracy have pointed out, working adults already have some sense of right and wrong and do have some experience with consequences, even though that experience may not have been factored in their decisionmaking process. Essentially, what ethics education has done for these adult students is to provide a logical frame or context to their everyday decisionmaking, where their primary reference is common sense knowledge (Adkins and Radtke 2004, p. 280; Gautschi III and Jones 1998, p. 212; Green and Weber 1997, p. 777).

These notions of workplace utility are particularly important for these adult students, who juggle work, family and studies. They will be inclined, therefore, to only pay attention to what has a direct impact on their lives, either in the workplace, or for the functional purpose of receiving a favourable grade. However, when they do see value in the knowledge they have gained, they are likely to commit to ethical behaviour, which is a direct rebuttal of the notion that managers only respond to financial and legal incentives or disincentives (Hooker 2004, p. 75).

\section{Organisational influence on workplace ethical behaviour}

This pilot study also suggests that the culture of the organisation and the nature of the industry are strong determinants in shifting an individual from ethical belief into ethical action. The stories support the notion that defiant organisations, such as the drilling industry illustrated in Harry's story, that do not deem ethical conduct as necessary behaviour (Sauser Jr 2013, p. 15), are likely to create an environment that threatens the surfacing of ethical concerns, even at the risk of termination of the individual who does so. Ethical conduct would also likely be oppressed in defiant organisations and at best humoured in compliant organisations (Adkins and Radtke 2004, p. 280; Caza et al. 2004, p. 170). Therefore, someone who has had negative experiences of ethical conduct at the workplace is unlikely to perceive any use value of ethics education, due to past experience at the workplace.

However, the stories also indicate a shift in attitudes, where success stories like those of Harry probably mark the shift to a more ethically nurturing culture. It also appears that the norm amongst organisations is to shift to a culture of compliance (Sauser Jr 2013 , p. 15), especially in this climate of declining moral standards and increased occurrences of ethical misconducts (Jennings 1999, p. 25; Luthar et al. 1997, p. 214). This is supported by the perspectives of "window dressing" (Wotruba et al. 2001, p. 61) and contrived attempts at compliance that were articulated in the stories, as illustrated in Vincent's account.

Interestingly, none of the stories indicated the existence of an organisation of character (Delaney and Sockell 1992, pp. 720-723; Sauser Jr 2013, pp. 16-17) where committed ethical leadership nurtures ethical conduct and behaviour. It is quite likely that the sample in this pilot study is too narrow to discover such an organisation, or perhaps this is an idealistic notion that struggles to exist in a materialistic business environment. If such an organisation did truly exist, the use and exchange value of ethics education would be appreciated beyond its instrumental outcomes. 


\section{Perceived value of ethics education}

The stories suggest congruence in the perception of the use value of ethics education. This can be attributed to the positive impact on the ethical development of the individuals who shared their stories, either in terms of making better sense of how they utilised common sense knowledge, or from the use and exchange value they derived at the workplace (Allen et al. 2005, pp. 176179; Freeman et al. 2009, p. 39). However, it seems that perceptions of use value could inadvertently be shaped upstream. Both Harry and Vincent lamented the relatively low weightage of the Applied Business Ethics compared to the other business study modules, seemed to give the impression that ethics education was less important, or of less value, than the other modules. Although this view was only explicitly expressed in two of the four stories, the importance of the place ethics education hold within the overall curriculum is supported by literature (Gurvitsh et al. 2017; Macfarlane and Ottewill 2004; Nastase and Gligor-Cimpoieru 2013; Sims and Brinkmann 2003). When perceptions of value are shaped even before the individual has had a chance to engage with the knowledge, that individual's approach to the module is likely to be largely instrumental; focus will be on receiving a pass grade rather than engage in the knowledge for practical application.

Although the quality of pedagogy may change this preconception, this is an area for further research. Hence, the manner in which the ethics module is positioned sets the tone for its perceived use value even before the student engages in the knowledge and experience. In the context of this specific research, the university concerned made the module a core requirement, which is a step in the right direction in emphasising ethics education.

\section{Conclusion}

This study sets out to examine the perceived and experienced utility of the Applied Business Ethics module taught in an undergraduate degree programme to part-time working adults. Perceptions of utility were unearthed through the personal stories of four of the students, who had graduated, using their descriptions of their lived experiences, learning the knowledge in the classroom, and then having an opportunity to apply that knowledge in the workplace.

While this pilot study is not making a claim on the holistic relation between the use and exchange value of applied business ethics education, the consistent themes from the four stories, albeit a small sample, seem to suggest that utility or use value is an important determinant of shaping exchange value. What seems to be surfacing is that when use value is reaped consistently over time, exchange value is perceived when the individual sees positive outcomes at the workplace, and in life, as a result of sustainable skills and behaviours. Use and exchange value are, therefore, two parts of a whole that are not mutually exclusive, and exchange value can only be derived when use value is perceived. Once the individual perceives the use value of ethics education, behaviour is more likely to be driven by that knowledge, and not just financial and legal incentives (or disincentives). 
However, the study also noted the powerful influence of organisational culture that nurtures, humours or denies ethical behaviour. Even if the individual finds use value in ethics education, a defiant organisational culture will prevent that individual from translating ethical thinking into ethical action, primarily because of self-preservation needs. An organisation of character will do exactly the opposite, hence reinforcing the perception of use value, which over time may translate to exchange value. However, such an organisation seems to be more of an ideal that could not be unearthed in this specific study, due to the pilot nature of this research, but it does suggest an area for more in-depth study. Nevertheless, it is safe to state, based on this pilot study, that working adults in Singapore do seem to appreciate the utility in the Applied Business Ethics module that was taught as part of their part-time undergraduate business degree. Therefore, current practitioner tutors engaging students in ethics education may wish to take a leaf from the Giving Voice to Values approach (Arce and Gentile 2015; Gentile 2014,2017 ) by focusing on enlightening students on the value proposition presented by ethical decision-making at the workplace, rather than making ethics education an intellectual debate or about changing student behaviour, leveraging on existing contextual opportunities available in management modules.

An area for further consideration is the positioning of Applied Business Ethics as a subject module as well as its place within the larger context of the business degree curriculum. While literature seems divided on issues like the stage at which ethics education should be introduced within the curriculum and its infusion into other business subjects, pedagogy and assessment, these are areas well worth considering for further research.

Open Access This article is distributed under the terms of the Creative Commons Attribution 4.0 International License (http://creativecommons.org/licenses/by/4.0/), which permits unrestricted use, distribution, and reproduction in any medium, provided you give appropriate credit to the original author(s) and the source, provide a link to the Creative Commons license, and indicate if changes were made.

\section{References}

Adkins, N., \& Radtke, R. R. (2004). Students' and faculty members' perceptions of the importance of business ethics and accounting ethics education: is there an expectations gap? Journal of Business Ethics, 51(3), 279-300.

Akerlind, G. (2005). Phenomenographic methods: a case illustration. In J. Bowden \& P. Green (Eds.), Doing developmental phenomenography (pp. 103-127). Melbourne: RMIT University Press.

Allen, W. R., Bacdayan, P., Berube Kowalski, K., \& Roy, M. H. (2005). Examining the impact of ethics training on business student values. Education and Training, 47(3), 170-182.

Alvermann, D. E. (2000). Narrative approaches. In M. L. Kamil, P. B. Mosenthal, P. D. Pearson \& R. Barr (Eds.), Handbook of reading research (pp. 123-139). New York: Routledge.

Arce, D. G., \& Gentile, M. C. (2015). Giving voice to values as a leverage point in business ethics education. Journal of Business Ethics, 131(3), 535-542.

Bailey, P. H., \& Tilley, S. (2002). Storytelling and the interpretation of meaning in qualitative research. Journal of Advanced Nursing, 38(6), 574-583.

Balotsky, E. R., \& Steingard, D. S. (2006). How teaching business ethics makes a difference: findings from an ethical learning model. Journal of Business Ethics Education, 3, 5-34.

Blythe, S., Wilkes, L., Jackson, D., \& Halcomb, E. (2013). The challenges of being an insider in storytelling research. Nurse Researcher, 21(1), 8-12.

Bruner, J. (1991). The narrative construction of reality. Critical Inquiry, 18, 1-21. 
Buckley, M. (2013). A constructivist approach to business ethics. Journal of Business Ethics, 117(4), 695-706.

Caza, A., Barker, B. A., \& Cameron, K. S. (2004). Ethics and ethos: the buffering and amplifying effects of ethical behavior and virtuousness. Journal of Business Ethics, 52(2), 169-178.

Couper, M. P. (2000). Review: web surveys: a review of issues and approaches. Public Opinion Quarterly, 64, $464-494$.

Crane, F. G. (2004). The teaching of business ethics: an imperative at business schools. Journal of Education for Business, 79(3), 149-151.

Creswell, J. W. (2002). Educational research: planning, conducting, and evaluating quantitative. Upper Saddle River: Prentice Hall.

Creswell, J. W. (2013). Research design: qualitative, quantitative, and mixed methods approaches. Thousand Oaks: Sage Publications.

De Jong, T., \& Ferguson-Hessler, M. G. (1996). Types and qualities of knowledge. Educational Psychologist, 31(2), 105-113.

Delaney, J. T., \& Sockell, D. (1992). Do company ethics training programs make a difference? An empirical analysis. Journal of Business Ethics, 11(9), 719-727.

Denzin, N. K., \& Lincoln, Y. S. (1994). Handbook of qualitative research. Thousand Oaks: Sage Publications, Inc.

Etzioni, A. (2002). B399-when it comes to ethics, B-schools get an F (p. B4).

Falk, J. L. (1956). Issues distinguishing idiographic from nomothetic approaches to personality theory. Psychological Review, 63(1), 53-62.

Freeman, R. E. (2004). The stakeholder approach revisited. Zeitschrift für Wirtschafts-und Unternehmensethik, 5(3), 228-241.

Freeman, R. E., Stewart, L., \& Moriarty, B. (2009). Teaching business ethics in the age of Madoff. Change: The Magazine of Higher Learning, 41(6), 37-42.

Friedman, M. (2002). The social responsibility of business is to increase its profits. Applied Ethics: Critical Concepts in Philosophy, 5, 57.

Gallagher, K. M. (2011). In search of a theoretical basis for storytelling in education research: story as method. International Journal of Research \& Method in Education, 34(1), 49-61.

Gautschi, F. H., III, \& Jones, T. M. (1998). Enhancing the ability of business students to recognize ethical issues: an empirical assessment of the effectiveness of a course in business ethics. Journal of Business Ethics, 17(2), 205-216.

Gentile, M. C. (1993). Engaging the power and competence of the faculty. In T. R. Piper, M. C. Gentile \& S. D. Parks (Eds.), Can ethics be taught? (pp. 73-115). USA: Harvard Business School Press.

Gentile, M. C. (2014). Giving voice to values: an action-oriented approach to values-driven leadership. SAM Advanced Management Journal, 79(4), 42.

Gentile, M. C. (2017). Giving voice to values: a pedagogy for behavioral ethics. Journal of Management Education, 41(4), 469-479.

Godsey, M. (2007). Ethics education. Journal of Business Ethics Education, 4, 55-77.

Green, S., \& Weber, J. (1997). Influencing ethical development: exposing students to the AICPA code of conduct. Journal of Business Ethics, 16(8), 777-790.

Gurvitsh, N., Alver, J., \& Alver, L. (2017). On the role and place of business ethics in the modern business world - evidence from Estonia. Zeszyty Teoretyczne Rachunkowości, 93(149), 79-95.

Hasnas, J. (1998). The normative theories of business ethics: a guide for the perplexed. Business Ethics Quarterly, 8(01), 19-42.

Hooker, J. (2004). The case against business ethics education. Journal of Business Ethics Education, 1(1), 7385.

Jansen, H. (2010). The logic of qualitative survey research and its position in the field of social research methods. Paper presented at the Forum Qualitative Sozialforschung/Forum: Qualitative Social Research.

Jennings, M. M. (1999). What's happening in business schools? The Public Interest, (137), 25.

Jones, T. M. (1991). Ethical decision making by individuals in organizations: an issue-contingent model. Academy of Management Review, 16(2), 366-395.

Keen, S. (1993). Use-value, exchange value, and the demise of Marx's labor theory of value. Journal of the History of Economic Thought, 15(01), 107-121.

Kvale, S., \& Brinkmann, S. (2009). Interviews: learning the craft of qualitative research interviewing. Sage. Lee, B. (2015). Storytelling to enhance the value of research. American Journal of Public Health, 105(4), e1e1.

Lester, S. (1999). An introduction to phenomenological research. Stan Lester Developments, 1-4.

Lewis, P. J. (2011). Storytelling as research/research as storytelling. Qualitative Inquiry, 17(6), 505-510. 
Luthar, H. K., DiBattista, R. A., \& Gautschi, T. (1997). Perception of what the ethical climate is and what it should be: the role of gender, academic status, and ethical education. Journal of Business Ethics, 16(2), 205-217.

Ma, Z. (2013). Business students' cheating in classroom and their propensity to cheat in the real world: a study of ethicality and practicality in China. Asian Journal of Business Ethics, 2(1), 65-78.

Macfarlane, B. (2011). The morphing of academic practice: unbundling and the rise of the para-academic. Higher Education Quarterly, 65(1), 59-73.

Macfarlane, B., \& Ottewill, R. (2004). Business ethics in the curriculum: assessing the evidence from UK subject review. Journal of Business Ethics, 54(4), 339-347.

Mulligan, T. (1986). A critique of Milton Friedman's essay 'the social responsibility of business is to increase its profits'. Journal of Business Ethics, 5(4), 265-269.

Nastase, M., \& Gligor-Cimpoieru, D. C. (2013). A plea for the importance of business ethics education for future managers in an international competitive environment. Revista de Management Comparat International, 14(2), 191.

Parks, S. D. (1993). Is it too late? Young adults and the formation of professional ethics. In T. R. Piper, M. C. Gentile \& S. D. Parks (Eds.), Can ethics be taught? (pp. 13-72). USA: Harvard Business School Press.

Rawwas, M. Y., \& Isakson, H. R. (2000). Ethics of tomorrow's business managers: the influence of personal beliefs and values, individual characteristics, and situational factors. Journal of Education for Business, 75(6), 321-330.

Repo, A. (1986a). The dual approach to the value of information. Information Processing and Management, 13(5), 373-383.

Repo, A. J. (1986b). The dual approach to the value of information: an appraisal of use and exchange values. Information Processing \& Management, 22(5), 373-383.

Ross, W. T., Jr., \& Robertson, D. C. (2003). A typology of situational factors: impact on salesperson decisionmaking about ethical issues. Journal of Business Ethics, 46(3), 213-234.

Royaee, R., Ahmadi, S. A., \& Jari, A. (2013). Students' and faculty members' perceptions of the importance of business ethics and accounting ethics education: Iranian case. Asian Journal of Business Ethics, 2(2), $163-171$.

Saat, M. M., Porter, S., \& Woodbine, G. (2010). An exploratory study of the impact of Malaysian ethics education on ethical sensitivity. Journal of Business Ethics Education, 7, 39-62.

Sabri, D. (2010). Absence of the academic from higher education policy. Journal of Education Policy, 25(2), 191-205.

Sauser, W. I., Jr. (2013). Empowering leaders to craft organizational cultures of character: conceptual framework and examples. Journal of Leadership, Accountability and Ethics, 10(1), 14.

Sims, R. R., \& Brinkmann, J. (2003). Business ethics curriculum design: suggestions and illustrations. Teaching Business Ethics, 7(1), 69-86.

Sinha, R. B. N., \& Hassan, A. (2015). Perceiving own and others behaviour: an exploration in social perception. International Journal of Business and Society, 16(1), 107.

Skeggs, B. (2004). Exchange, value and affect: Bourdieu and 'the self'. The Sociological Review, 52(s2), 7595.

Smith, J. A., \& Eatough, V. (2007). Interpretative phenomenological analysis. In E. Lyons \& A. Coyle (Eds.), Analysing qualitative data in psychology. London: Sage.

Smyth, A., \& Holian, R. (2008). Credibility issues in research from within organisations. In P. Sikes \& A. Potts (Eds.), Researching education from the inside: investigations from within (pp. 33-47). New York: Routledge.

Warnell, J. M. (2010). An undergraduate business ethics curriculum: learning and moral development outcomes. Journal of Business Ethics Education, 7, 63-83.

Whitchurch, C. (2009). The rise of the blended professional in higher education: a comparison between the United Kingdom, Australia and the United States. Higher Education, 58(3), 407-418.

Winch, C. (2002). The economic aims of education. Journal of Philosophy of Education, 36(1), 101-117.

Wotruba, T. R., Chonko, L. B., \& Loe, T. W. (2001). The impact of ethics code familiarity on manager behavior. Journal of Business Ethics, 33(1), 59-69.

Yoder-Wise, P. S., \& Kowalski, K. (2003). The power of storytelling. Nursing Outlook, 51(1), 37-42.

Publisher's note Springer Nature remains neutral with regard to jurisdictional claims in published maps and institutional affiliations. 